\title{
Analysis of cost of various topical and oral antifungal drugs for superficial fungal infections available in India
}

\author{
Spoorthy H. V.*, L. Padma, Srividya B. P.
}

Department of Pharmacology, Sapthagiri Institute of Medical Sciences and Research Center, Hesraghtta Road, Bangalore, Karnataka, India

Received: 03 October 2021

Revised: 06 November 2021

Accepted: 08 November 2021

\section{*Correspondence:}

Dr. Spoorthy H. V.,

Email: spoorthyvasanth@gmail.com

Copyright: $@$ the author(s), publisher and licensee Medip Academy. This is an open-access article distributed under the terms of the Creative Commons Attribution Non-Commercial License, which permits unrestricted non-commercial use, distribution, and reproduction in any medium, provided the original work is properly cited.

\begin{abstract}
Background: In tropical countries like India, superficial fungal infections are quite common and certain infections like tinea is rampantly spreading in epidemic proportions and frequent relapses after treatment have increased the need for long term therapy significantly increasing the cost of treatment, so the treatment of fungal infection can raise economic burden on the patient. The aim of the study was to analyze the cost variation of topical antifungal drugs and oral antifungal drugs of various brands for superficial fungal infection available in India.

Methods: Cost in Indian Rupees (INR) of antifungal agents manufactured by different pharmaceutical companies in India was collected from the Current index of medical specialities (CIMS) October to December 2019. Minimum cost, maximum cost, cost ratio, cost variation was calculated.

Results: In oral dosage form, fluconazole, Itraconazole show the maximum cost variation. In topical single drug therapy luliconazole, terbinafine show maximum cost variation.

Conclusions: There is wide cost variation among antifungal agents available in Indian Market. There is need of strict actions for cost policy regulation and sensitization of doctor for selection of appropriate brand drugs.
\end{abstract}

Keywords: Cost analysis, Antifungal drugs, Topical antifungals

\section{INTRODUCTION}

Superficial fungal infections of the hair, skin and nails are a major cause of morbidity in the world, particularly in the tropics like India where heat and humidity provide the ideal conditions for the growth of fungi that cause cutaneous infections. ${ }^{1}$ Also Economic (poor hygiene) and social (overcrowding) causes are known to adversely influence the course of the infections. ${ }^{2}$

Certain fungal infections like tinea is rampantly spreading in epidemic proportions and frequent relapses after treatment have increased the need for long term therapy significantly increasing the cost of treatment, so the treatment of fungal infection can raise economic burden on the patient. Increased cost of treatment is associated with the poor patient compliance and outcome. In developing country like India; drug costs form a significant portion of treatment cost, approximately 30 to $40 \%$. It is a concerning signs not only for patients, but also for policy makers and service providers. So, efforts should be made to choose the drug with minimum cost without affecting efficacy of the drugs. $^{3}$

Topical Antifungal drugs available in Indian market for treatment of superficial fungal infection in different dosage forms are Clotrimazole, Ketoconazole Miconozole, Luliconazole, Eberconazole, Sertaconazole, Oxiconazole Fentaconzole, Terbinafine, Amorolfine. ${ }^{4}$ Sertaconazole, Oxiconazole Fentaconzole, Terbinafine, Amorolfine. ${ }^{5}$ Systemic antifungal drugs available are 
fluconazole, itraconazole, ketoconazole, terbinafin, griseofulvin in different dosage and oral dosage forms. ${ }^{5}$

Large number of generic drugs and branded formulations of above-mentioned drug available in Indian market and Indian pharmaceutical industries are one of the largest pharmaceuticals in the world. $^{7}$ Due to Insufficient information about wide variation in drug cost, quality, bioequivalence makes it difficult for the physician to prescribe the most cost-effective treatment. ${ }^{6}$

With the above points in the mind, limited studies are available in Indian scenario regarding price variation analysis of both systemic and topical antifungal drugs. The present study is aimed at finding variation in price of various brands of same generic antifungal drugs available in Indian market. ${ }^{7}$

\section{Objectives of the study}

To analyze the cost variation of topical antifungal drugs of various brands for superficial fungal infection available in India. To analyze the cost variation of oral antifungal drugs of various brands for superficial fungal infection available in India.

\section{METHODS}

Cost in Indian Rupees (INR) of particular antifungal drug in the same strength, number, and dosage forms being manufactured by different pharmaceutical companies in India was obtained from the Current Index of Medical Specialities (CIMS) October to December 2019 and 1mg online app as these are readily available sources of drug information. CIMS is considered authentic and trusted source of commercial drug information. Fixed dose combinations of different antifungals and with steroids were excluded in the study.

Minimum and Maximum cost, Difference in maximum and minimum cost of the same drug manufactured by different companies and percentage cost variation was calculated using formula.

$$
\begin{aligned}
\text { Cost variation } & (\%) \\
& =(\max \cos t \\
& -\min \cos t) \times 100 \div \min \cos t
\end{aligned}
$$

For study purpose among topical preparation cost for $30 \mathrm{~g}$ cream is taken since it is most commonly prescribed.

\section{Statistical analysis}

The collected data was entered in Microsoft excel 2007 and analyzed for percentage cost variation and cost difference of individual drugs. The findings expressed in number and percentages.

\section{RESULTS}

The price of 10 topical antifungal drugs and 5 oral antifungal drugs available in different formulations from "current index of medical specialities" October to December 2019 and one mg app were analysed. Table 1 shows number of companies manufacturing brand version of generic drugs, maximum cost, minimum cost, cost variation of $30 \mathrm{~g}$ cream of topical antifungal drugs.

Table 1: Cost variation on topical antifungal agents.

\begin{tabular}{|lllll|l|}
\hline Name of the drug & $\begin{array}{l}\text { Manufacturing } \\
\text { companies }\end{array}$ & $\begin{array}{l}\text { Minimum } \\
\text { cost }\end{array}$ & $\begin{array}{l}\text { Maximum } \\
\text { cost }\end{array}$ & $\begin{array}{l}\text { Cost } \\
\text { difference }\end{array}$ & $\begin{array}{l}\text { Cost variation } \\
\text { Clotrimazole }\end{array}$ \\
\hline Ketoconazole & 3 & 82.66 & 146 & 63.34 & 76.63 \\
\hline Miconozole & 8 & 110 & 290 & 180 & 163.64 \\
\hline Luliconazole & 66 & 43.5 & 120 & 76.5 & 175.86 \\
\hline Eberconazole & 16 & 82 & 385 & 303 & 369.51 \\
\hline Sertaconazole & 21 & 290 & 387 & 97 & 33.45 \\
\hline Oxiconazole & 4 & 213 & 347 & 134 & 62.91 \\
\hline Fentaconzole & 5 & 85 & 180 & 95 & 111.76 \\
\hline Terbinafine & 13 & 185 & 249 & 64 & 34.59 \\
\hline Amorolfine & 19 & 61 & 197.5 & 136.5 & 223.77 \\
\hline
\end{tabular}

Table 2: Cost variation of oral antifungal drugs.

\begin{tabular}{|lllllll|}
$\begin{array}{l}\text { Name of the } \\
\text { drug }\end{array}$ & Dose & $\begin{array}{l}\text { Manufacturing } \\
\text { companies }\end{array}$ & $\begin{array}{l}\text { Minimum } \\
\text { cost }\end{array}$ & $\begin{array}{l}\text { Maximum } \\
\text { cost }\end{array}$ & Cost difference & \% Cost variation \\
\hline \multirow{2}{*}{$\begin{array}{l}\text { Fluconazole } \\
\text { tablet }\end{array}$} & $50 \mathrm{mg}$ & 29 & 33.45 & 265.62 & 232.17 & 694.08 \\
\hline & $150 \mathrm{mg}$ & 568 & 19 & 450 & 431 & 2268.42 \\
\hline $\begin{array}{l}\text { Itraconazole } \\
\text { capsule }\end{array}$ & $\mathbf{2 0 0 \mathrm { mg }}$ & 70 & 90 & 480 & 390 & 433.33 \\
\hline
\end{tabular}




\begin{tabular}{|lllllll|}
\hline $\begin{array}{l}\text { Name of the } \\
\text { drug }\end{array}$ & Dose & $\begin{array}{l}\text { Manufacturing } \\
\text { companies }\end{array}$ & $\begin{array}{l}\text { Minimum } \\
\text { cost }\end{array}$ & $\begin{array}{l}\text { Maximum } \\
\text { cost }\end{array}$ & Cost difference & \% Cost variation \\
\hline $\begin{array}{l}\text { Ketoconazole } \\
\text { tablet }\end{array}$ & $400 \mathrm{mg}$ & 4 & 300 & 400 & 100 & 33.33 \\
\hline $\begin{array}{l}\text { Terbinafine } \\
\text { tablet }\end{array}$ & $200 \mathrm{mg}$ & 85 & 100 & 304 & 204 & 204.00 \\
\hline $\begin{array}{l}\text { Griseofulvin } \\
\text { tablet }\end{array}$ & $250 \mathrm{mg}$ & 227 & 102.42 & 421 & 318.58 & 311.05 \\
\hline
\end{tabular}

Eberconazole cream $30 \mathrm{gm}$ is manufactured by 16 companies showed minimum cost variation (33.4\%).

Table 2 shows number of companies manufacturing brand version of oral generic antifungal drugs, maximum cost, minimum cost of different dosages also cost variation.

In our research, among the oral antifungals Fluconazole $150 \mathrm{mg}$ showed maximum \% cost variation (2268\%).

It is manufactured by 568 companies Itraconazole $400 \mathrm{mg}$ showed minimum $\%$ cost variation $(33 \%)$.

Itraconazole $400 \mathrm{mg}$ is manufactured by only 4 companies whereas $100 \mathrm{mg} \mathrm{n} \mathrm{200mg} \mathrm{is} \mathrm{manufactured} \mathrm{by} 485$ companies and has high $\%$ cost variation $(844 \%$ and $805 \%)$.

\section{DISCUSSION}

The present study calculated the percentage cost variation among different antifungal drugs with different brand names by using CIMS and $1 \mathrm{mg}$ app.

Our study showed a wide variation in the cost of antifungal drugs both topical and oral which are manufactured by different companies in different brand names.

In a cost variation study done only on oral antifungal drugs by Tiwari et al, showed fluconazole $150 \mathrm{mg}$ (10214\%) had maximum percentage cost variation which is in consistent with the findings of the present study. ${ }^{2}$

It is evident from present study that there is a wide discrepancy in the price of antifungal drugs in the Indian market. In a country like India, patients has to pay money for their medical bills which is not covered by the insurance companies/schemes, if costly drugs are prescribed to the patients, it leads to unnecessary economic burden to patients and if low cost drugs are prescribed efficacy may be less and no clinical outcome is seen sometimes. $^{8}$

This creates dilemma for physician in prescription of proper medication to the patients. Sometimes unawareness of the physician regarding wide cost variation and companies offering incentives to the physician for prescribing a particular brand and even pharmacist does not dispense the same brand as prescribed by the physician and substitute it with some other brand and reasoning as non-availability are some reasons. This is done for the higher profit margin and economic gains with some brands. While inadequate government regulation and pricing policies, raw material cost, promotion and distribution cost, existing market structure, asymmetry of information could also be the possible reasons for wide cost variation. ${ }^{9}$

Government issued an order called Drug price control order (DPCO) to fix prices of drug which cannot be sold at a price higher than that fixed by the government. Hence there is need for government to bring all life-saving and essential medicines under DPCO.

Pharmacoeconomics analysis helps in therapeutic decision making, formulary decision making, program justification, drug policy decisions and treatment guidelines ultimately benefitting the society in terms of availability of affordable drugs and reduction in healthcare expenses. ${ }^{10}$

In India, a particular drug is sold under different brand names by different pharmaceutical company along with their innovator company. Hence for a particular drug, a large number of formulations are available at different prices. Higher medication costs are an important factor for medication nonadherence. ${ }^{11}$

Therefore, there is a need for coordinated action from pharmaceutical companies, physicians, pharmacists, regulatory authorities as well as general public at large to address the problem of huge variation in the cost of the drugs.

The limitation of the study is that fixed dose combination of antifungals and steroids is not included even though most commonly prescribed by general practitioners since they lead to development of resistance and also sources of information were limited to CIMS and $1 \mathrm{mg}$ app few other brands of antifungal drugs which are marketed in India were not included in this study. ${ }^{12}$

\section{Limitations of our study}

Our study includes references of brands which are available only in CIMS and $1 \mathrm{MG}$ application, there are many local brands which are not yet updated in these two 
applications. Only standard topical formulations are mentioned in the study, combination creams, variable concentration of same topical agent has not been discussed. Among oral antifungals, nowadays combination of oral agents(terbinafine+griseofulvin) is available which is not included in our study.

\section{CONCLUSION}

There is wide cost variation among antifungal agents available in Indian Market. Superficial fungal infections require long term therapy in most of the cases. Important contributing factors for failure of treatment are compliance and cost burden. There is need of strict actions for cost policy regulation (DCGI) and sensitization of doctor for selection of appropriate brand drugs.

\section{Funding: No funding sources}

Conflict of interest: None declared

Ethical approval: The study was approved by the Institutional Ethics Committee

\section{REFERENCES}

1. Verma S, Madhu R. The Great Indian Epidemic of Superficial Dermatophytosis: An Appraisal. Indian J Dermatol. 2017;62(3):227-36.

2. Tiwari A. Cost analysis of anti-fungal drugs available in India: A pharmacoeconomic perspective. Indian J Pharm Pharmacol. 2016;3:192-6.

3. Lakshmanan A, Ganeshkumar P, Mohan SR, Hemamalini M, Madhavan R. Epidemiological and clinical pattern of dermatomycoses in rural India. Indian J Med Microbiol. 2015;33:134-6.

4. Bhavisha N, Vegada, Sohil P, Makwana, Shah A. Cost Variation Analysis of Antifungal Agents Available In
Indian Market. Saud J Med Pharm Sci. 2019;5(1):4953.

5. Sahni K, Singh S, Dogra S. Newer Topical Treatments in Skin and Nail Dermatophyte Infections. Indian Dermatol Online J. 2018;9(3):149-58.

6. Sheehan DJ, Hitchcock CA, Sibley CM. Current and Emerging Azole Antifungal Agents. Clin Microbiol Rev. 1999;12(1):40-79.

7. V YPGAPB. Analysis of pricing of oral antiviral drug formulations available in Indian market. Natl J Physiol Pharm Pharmacol. 2019;9(5):401-4.

8. Nomura K, Kawasugi $\mathrm{K}$, Morimoto $\mathrm{T}$. Costeffectiveness analysis of antifungal treatment for patients on chemotherapy. Eur J Cancer Care (Engl). 2006;15(1):44-50.

9. Verma SB. Complex Cost Issues in Treating Dermatophytoses in India_- "It All Builds Up." Indian Dermatol Online J. 2019;10(4):441-3.

10. Ahmad A, Patel I, Parimilakrishnan S, Mohanta GP, Chung H, Chang J. The role of pharmacoeconomics in current Indian healthcare system. J Res Pharm Pract. 2013;2(1):3-9.

11. Oberoi SS, Oberoi A. Pharmacoeconomics guidelines: The need of hour for India. Int $\mathbf{J}$ Pharm Investig. 2014;4(3):109-11.

12. Singh H, Mohan P, Kumar R, Gupta YK. Difference in described indications of medicines among drug information sources in India: An issue urgently to be addressed. J Nat Sci Biol Med. 2016;7(1):93-7.

Cite this article as: Spoorthy HV, Padma L, Srividya BP. Analysis of cost of various topical and oral antifungal drugs for superficial fungal infections available in India. Int J Basic Clin Pharmacol 2021;10:1348-51. 